\title{
Resident's strategy survey on a new end use of recycled water in Australia
}

\author{
H. H. Ngo ${ }^{a}$, H. Chuang ${ }^{a}$, W.S. Guo ${ }^{a}$, D. P. Ho ${ }^{a}$, T. T. N. Pham ${ }^{a}$, A. \\ Johnston ${ }^{\mathrm{a}}, \mathrm{R}$. Lim $^{\mathrm{b}}$ and A. Listowski ${ }^{\mathrm{c}}$ \\ ${ }^{a}$ School of Civil and Environmental Engineering, University of Technology Sydney, \\ Broadway, NSW 2007, Australia \\ Tel: +61 (2) 95141693, Fax: + 61(2) 95142633, Email: h.ngo@uts.edu.au \\ ${ }^{b}$ Institute of Water and Environmental Resource and management, University of \\ Technology Sydney, Broadway, NSW 2007, Australia \\ ${ }^{c}$ Sydney Olympic Park Authority, Sydney Olympic Park, NSW 2127, Australia
}

\begin{abstract}
The concept of using recycled water for washing machine was introduced as a new end use. As there is a noticeable lack social research in understanding the general public perceptions of this application, the resident's strategy survey was carried out at some selective suburbs in Sydney with demographically based significant differences of general, gender, age, education, and property style and ownership.
\end{abstract}

The survey indicates that the majority in the community considers the use of recycled water for washing machine is indispensable in view of continuing drought and the associated water shortages. Given safety assurance and demonstration, recycled water for washing machine has a considerable proportion within the responses.

The general level of knowledge in community clearly understand that recycled water is more environmentally friendly option, whereas from cleanness and public health point of view, higher quality water is required to be reused in washing machine. Moreover, the residents reckon to have a small unit for pre-treatment (point of use) before recycled water entering washing machines might assure the quality and safety. 
The survey also shows the major concerns for a resident to use recycled water for washing machine are public health, water cleanness and washing machine durability.

Keywords: Recycled water, water shortages, new end use, resident's strategy survey, public health, water cleanness, washing machine durability

* Corresponding author

\section{Introduction}

Pressure on the availability of Australian freshwater resources is significantly increasing due to emerging climate change and population growth factors [1]. Water recycling is therefore considered vital in alleviating the demand on existing and limited water supplies while helping to protect remaining water sources from being polluted. As an important element of water resource development and management, the use of recycled water can help to close the loop between water supply and wastewater disposal. In the Australian context, demands on water utilities to develop water recycling capacity and supplies are expected to intensify. It is now recognized that recycled water is a valuable resource that has potential to free up potable water supplies and recharge systems while improving the environment [2]. Currently, recycled water in Sydney is estimated at approximately 15 billion liters per year from a total of 450 billion liters of collected wastewater while approximately $41 \%$ of recycled water is used to replace tap water use [3]. 
Recycled water has proven to be effective and successful in creating a new and reliable water supply. Non-potable reuse is a widely accepted practice that is likely to continue to grow. The uses of recycled water should expand further in order to accommodate increasing needs of the environment and to satisfy growing water demands. Urban water reuse has been hampered by a number of factors including the lack of appropriate and uniform recycled water quality standards, poor risk management practices, and inadequate public education resulting in limited acceptance of recycled water by consumers. Although the disadvantage of water recycling exists due to additional costs of wastewater treatment, storage, additional pumping, separate distribution system, additional management and increased health risk etc., in many cases, these additional costs may be recovered over time through water savings, free capacity of water and sewage infrastructure etc. [4, 5].

With a country of 20 million people, Australia projects a $33 \%$ population increase in urban areas by 2030 [6]. As a result of this population growth, a serious shortage of catchment capacity for water supply is developing in coastal cities. It is estimated that even if Australia were to cut per capita water use by $7 \%$ and one-quarter of new suburbs were to use recycled water for outdoor activities and toilet flushing, the country would still face a shortfall in supply of 800 GL by 2030 [7]. At present recycled water is mainly used for irrigation and toilet/urinal flushing or car washing but not for laundry use. According to statistics in the NSW State of the Environment Report [8] on typical water usage in Sydney metropolitan households, laundry use requires up to $20 \%$ of total water consumption. Large-scale municipal recycled water schemes, such as those of the Rouse Hill Development Area (RHDA) and Sydney Olympic Park Authority (SOPA) traditionally provide recycled water for outdoor 
garden use and toilet flushing at a total saving of approximately $35 \%$ of potable water use. The addition of washing machines to recycled water end use is estimated to increase this value to $45 \%$.

Although some previous surveys showed the positive response for recycled water concept by public, there were some failure projects for recycled water even they were initially supported by local communities. These particular failure cases have been investigated and analysed by Melbourne Water [9] and Water Corporation of WA [10]. From their reports, the key factors to explain the failures were found to be: (i) disgust or "yuck" factor, (ii) perceptions of risk associated with using recycled water, (iii) sources of water to be recycled, (iv) issue of choice, (v) trust and knowledge, (vi) attitudes toward the environment, (vii) environmental justice issues and cost of recycled water.

The inclusion of recycled water as cold water supply for washing machines into the range of non-potable water end uses in dwellings will allow additional wastewater to be recycled. However, government agencies or water authorities can only fully implement this end use until all remaining questions including both of scientific based evidence and ultimate customer acceptance issues are resolved. Thus, this study aims to provide a resident's strategy survey and evaluation of the use of recycled water for washing machines. 


\section{Methodology}

\section{$\underline{\text { Education leaflet }}$}

Prior to formulate the survey questionnaire, an education leaflet was established to provide the fundamental knowledge regarding recycled water on the issues: (i) What are recycled water, drinking water, grey water, storm water and groundwater?; (ii) Why recycle water?; (iii) How safe is recycled water?; (iv) What are the potential risks associated with recycled water?; and (v) What has recycled water been used in Australia to date?. This leaflet aims to enhance public understanding and knowledge before they complete the survey.

\section{$\underline{\text { Survey questionnaire }}$}

The survey questionnaire was designed to cover the following topics:

- The community is familiar with the concept of recycled water

- Level of community support for the various uses of recycled water

- Community concern, risk perception and trust

- The impact of impartial communication on people's views about and support for recycled water.

- Extent of concern about water shortages

- Willingness to use recycled water for washing machine

- Extent of concern about recycled water side effect to the washing machine.

- Association of recycled water with various attributes

- Views on the price of recycled water and its impact on water consumption 


\section{$\underline{\text { Survey approach }}$}

The survey was conducted in representative suburbs of northern, southern, western and eastern Sydney (Table 1). Respondents from Western suburbs accounts for 1/3 of the population, and the remaining were distributed evenly from the other regions. Most of the people interviewed were from 20 to 40 years old, accounting for more than $75 \%$ of the surveyed population (Figure 1). The respondents' occupations covered various areas, such as IT, finance and business, education, health, engineering, accounting and counselling. Retired and housewives also contributed to $12 \%$ of the population as the survey was mainly conducted in shopping centres.

The survey was conducted among 223 people by direct interview and online questionnaires. The respondents were then categorized in different age groups, suburbs and backgrounds.

Table 1

Summary of surveyed suburbs

\begin{tabular}{|l|l|}
\hline East & $\begin{array}{l}\text { Darlinghurst, Surry Hills, Mascot, Clovelly, Kingsford, Kensington, } \\
\text { Coogee, Maroubra, Port Botany, Kingsford }\end{array}$ \\
\hline North & $\begin{array}{l}\text { Milsons Point, Artarmon, Willoughby, Northbridge, Lindfield, } \\
\text { Cremorne, Chatswood, Epping, West Ryde }\end{array}$ \\
\hline South & $\begin{array}{l}\text { Penshurst, Sydenham, Rockdale, Kingsgrove, Sutherland, } \\
\text { Hurstville, Wolli Creek }\end{array}$ \\
\hline West & $\begin{array}{l}\text { Enmore, Newtown, Marrickville, Canterbury, Bankstown, } \\
\text { Paramatta, Strathfield, Newington, Croydon Park, Lidcombe, } \\
\text { Earlwood, Fairfield, Burwood, Merrylands }\end{array}$ \\
\hline Sydney & Ultimo, Glebe, Redfern, Chippendale, Pyrmont \\
\hline
\end{tabular}




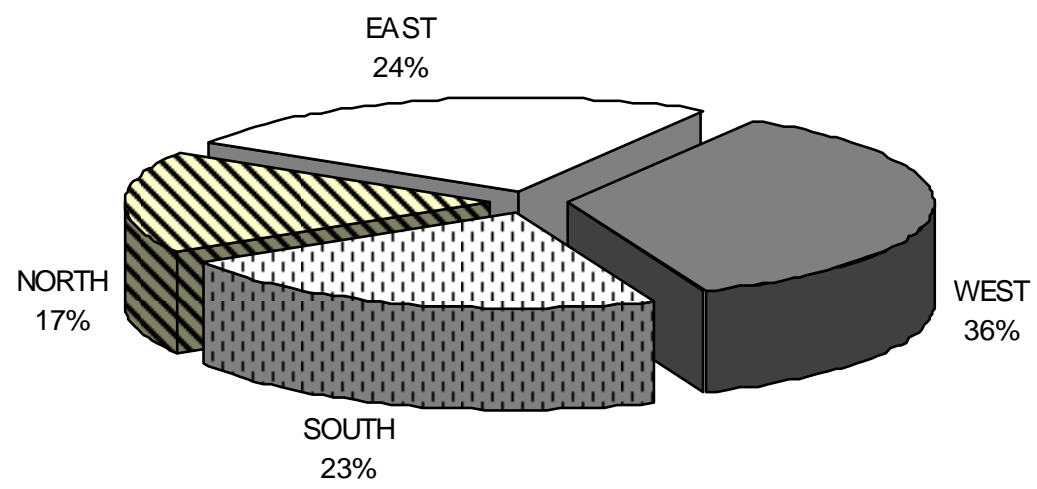

Fig. 1 Percentages of respondents from different regions around Sydney

\section{Survey results and analysis}

\section{Concern about water shortages}

Views on recycled water should be looked at the background of general concern about current water situation. To measure how prominent water shortages are relative to other present social and environmental matters, participants were asked to consider a set of seven issues and to indicate which the highest concern to them is. Table 2 summarizes the seven issues and the percentage who mentioned them as the first concern for the total sample. The results indicated that water shortages are the most conspicuous area of concern, rated by $55 \%$ of respondents, and are much ahead of the next most important issue - health services (rated as first concern by $13 \%$ of respondents). 
$\underline{\text { Familiarity with the concept of recycled water }}$

Table 3 shows responses to a question which asked people to describe the level of their knowledge on recycled water. Most of the people interviewed admitted that they know very little to quite a bit on recycled water. The majority agreed that recycled water should be a prerequisite for dealing with water shortages. Besides, people who claim to know a lot or quite a bit about recycled water are more likely to be among: (i) males rather than females, (ii) people with high education and (iii) people who live in house rather than those who live at unit or apartment.

Table 2

Percentage of respondents who mention each issue as first concern

\begin{tabular}{cc}
\hline & \% of the total sample \\
\hline Water Shortage & 55 \\
Health services & 13 \\
Climate Change & 11 \\
Drugs & 6 \\
Public Transport & 6 \\
Terrorism & 5 \\
Air Pollution & 3 \\
\hline
\end{tabular}

Table 3

Familiar with the concept on recycled water

\begin{tabular}{|c|c|}
\hline & Percentage \% \\
\hline A lot & 11 \\
Quite a bit & 22 \\
A little bit & 56 \\
Nothing & 10 \\
\hline
\end{tabular}




\section{Willingness to use recycled water for washing machine}

In all the suburbs, more than $60 \%$ participants support using recycled water for washing machines. About one-third of people are still indecisive and less than $10 \%$ against the idea (Figure 2). However, there are no significant different opinions between gender and education level. Among the household personal, non-food related purposes, washing clothes in recycled water has more than 55\% to the largest proportion of respondents. Just less than one half are very willing to use recycled water for home pools and about one third are very willing to use it for showering or washing purposes.

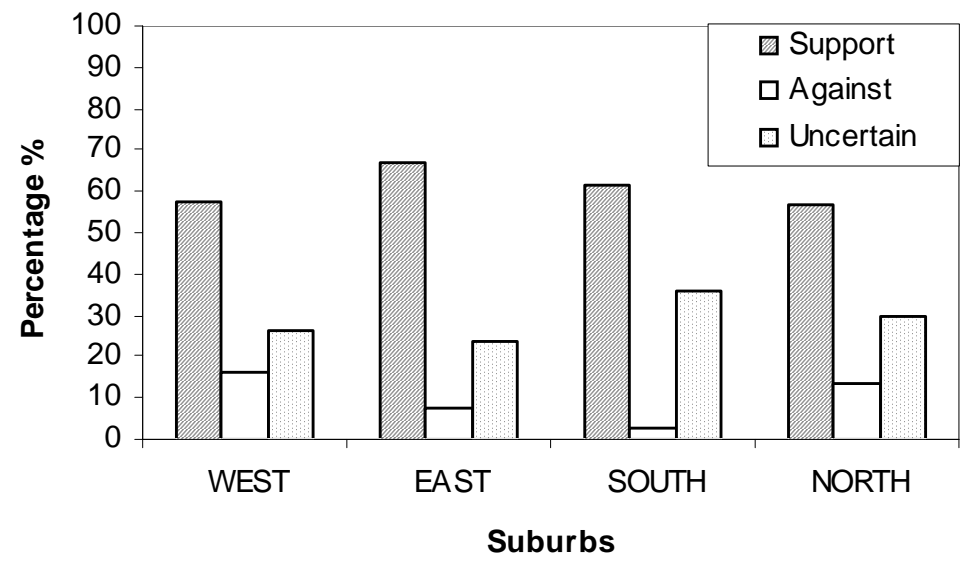

Fig. 2. Opinions of respondents in different suburbs in Sydney

\section{Concern with aspects of the use of recycled water to wash clothes}

Table 4 indicates that about $3 / 4$ of people responded that hygiene, smell and health are their most considerable concerns. About $1 / 3$ of respondents worried about discoloration of clothes while the rest care about durability of washing machines, 
water quality and cost. Approximate half of the people interviewed said they would feel more secure if having a small unit for pre-treatment. On the other hand, one third want to watch a known scientist to confirm the water quality before use while another third said they would accept to use recycled water if knowing other cities are safely using it too (Table 5).

Table 4

Respondents' concerns over using recycled water for washing machine

\begin{tabular}{cc}
\hline Concerns & \% \\
\hline Durability of washing machine & 13.4 \\
Discoloration & 26.2 \\
Health & 57.0 \\
Hygiene, smell & 73.8 \\
Cost & 16.3 \\
Water quality & 11.0 \\
\hline
\end{tabular}

Table 5

Further conditions to consider using recycled water for washing machine

\begin{tabular}{lcccc}
\hline & East & West & North & South \\
\hline - & 62 & 36 & 60 & 49 \\
$\begin{array}{l}\text { Having a small unit for pre- } \\
\text { treatment to assure the quality and } \\
\text { safety of the water }\end{array}$ & 26 & 38 & 40 & 46 \\
- $\begin{array}{l}\text { Knowing that people in other cities } \\
\text { use recycled water for washing } \\
\text { machine }\end{array}$ & 14 & 15 & 13 & 28 \\
- $\begin{array}{l}\text { Being told that the water situation } \\
\text { is so severe that we have to use } \\
\text { recycled water }\end{array}$ & 26 & 34 & 60 & 28 \\
- Watching a known scientist & 19 & 5 & 17 & 8 \\
$\begin{array}{l}\text { confirming it } \\
\text { Knowing that it will be combined } \\
\text { with the existing water supply }\end{array}$ & 19 & & & \\
\hline
\end{tabular}

Views on the price water and its impact on consumption

The opinions of respondents on the cost of recycled water for washing machine are distributed evenly (Figure 3). One third expected the cost would reduce. Another third anticipated think the cost would increase due to the installation and treatment cost. The remaining said the cost would remain the same. 
A considerable proportion of the participants $(46 \%)$ believe that if recycled water is introduced for washing machines, people will use more water, while $42 \%$ suppose that the introduction of recycled water will have no impact on water usage and only $11 \%$ think people will use less water.

When being asked whether it is worth to install recycled water system if it is costly, more than $50 \%$ agreed in saying it is good for the environment and would be the alternative for limited water resources. About 20\% oppose against the recycled schemes and suggest the money should be spent on something else or worry that the cost would be charged from consumers (Table 6).

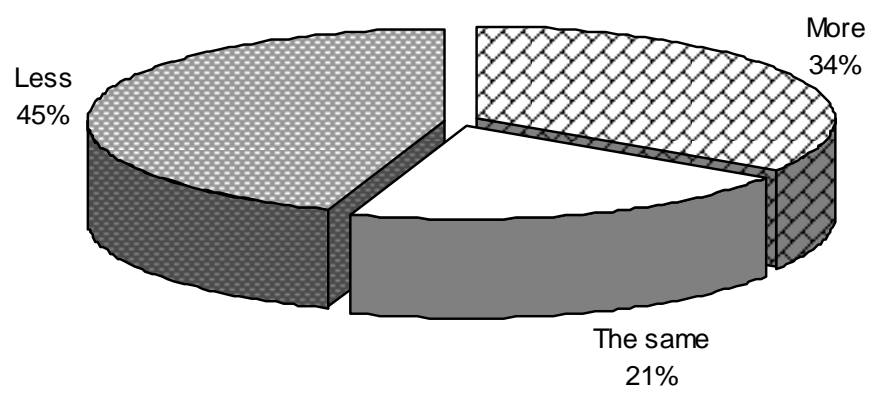

Fig. 3. Expected cost of recycled water for washing machine

Table 6

Opinions of respondents on the benefit of installing recycled water system for washing machine

\begin{tabular}{lc}
\hline Answers & Percentage \% \\
\hline Yes, its good for environment & 58 \\
Yes, to have more water resources & 41 \\
No, money should be spent on something else & 12 \\
No, it would cost more on consumers & 8 \\
Other reasons & 1 \\
\hline
\end{tabular}




\section{Demographically based significant differences}

General: Majority of participants stand out in their response to the survey more mention water shortages as their first concern and are extremely worried about the water situation. They are more than willing to use recycled water for many of the purposes and more associate most of the recycled water for washing machine with the positive attributes and fewer with the negative attributes.

Gender: More females than males express concern about recycled water for washing machine and other various aspects.

Age: There is a tendency for older respondents to be less concerned about aspects of recycled water than younger ones.

Education: The higher level of education, the stronger tendency to support the various aspects of recycled water.

Property style and ownership

There is a tendency for more respondents who live in house are more likely to know about recycled water than those who live in unit or apartment. The property owners believe that they will intend to use more water than people who rent the property if recycled water scheme being introduced. 


\section{Conclusion}

The significance of public acceptance for a successful recycled water scheme is widely recognized. However, there is a noticeable lack social research in understanding the general of public perceptions of water reuse in washing machine and some other critical factors associating their decision making processes. The survey indicated that the majority in the community consider the introduction of recycled water for washing machine to be expected in view of continuing drought and the associated water shortages. The major concerns for public to use recycled water for washing machine are public health, water clearness and machine durability. Thus, recycled water quality is one of the most important factors which can affect the public perception on the application of this new end use.

Since this work is just a preliminary resident's strategy survey, further investigations are necessary to focus on the topics of: (i) strategies to understand public perception, (ii) identification of the critical factors collected from public's concerns, (iii) investigation of how apparent technology advantages in using recycled water can facilitate people's decisions to use recycled water for washing machine, and (vi) understanding of possible environmental issues which can affect people's willingness to use recycled water. (iii) investigation of the role of belief in relative water authorities and scientific understanding in people's judgment making processes to either for or against the use of recycled water for washing machine, (iv) conclusion of different ways and situations where factors such as health, environment, treatment, distribution and conservation issues can influence people's acceptance to use recycled water, (v) investigation of how apparent technology advantages in using recycled 
water can facilitate people's decisions to use recycled water for washing machine, and (vi) understanding of possible environmental issues which can affect people's willingness to use recycled water.

\section{Acknowledgment}

This study was funded by UTS Challenge Grant.

\section{References}

[1] Dismitriadis, S. (2005). Issues encountered in advancing Australia's water recycling schemes, Research Brief, Partliament of Australia, Department of Parliamentary Srvices, No.2, 4- 43.

[2] Asano, T. (2001). Water from wastewater - the dependable water resource, the $11^{\text {th }}$ Stockholm Water Symposium, Stockholm, Sweden, 12-18.

[3] NSW Government (2006). Metropolitan water plan, Chapter 5: Recycling Water, $29-50$.

[4] Kaspura, A. (2006). Water and Australian cities - Review of urban water reform, Engineers Australia, 1-83.

[5] Thomas, J. F., Adams, P., Dixon, P., Hall, N. and Watson, W. (1999). Water and Australian economy. Australian Academy of Technological Sciences and Engineering and the Institution of Engineers

[6] Young, R. (2005). National trends in urban water resource management, Address to Gold Coast Water Future Advisory Committee, Water Services Association of Australia. 
[7] Howe, C. (2005). Climate change scenarios, implications for the Australian urban water industry, Ozwater watershed - the turning point of water, Brisbane, p.6.

[8] NSW State of the Environment (2003). Typical household water use in Sydney, InformationlWater Demand - City of Sydney.htm.

[9] Melbourne Water (1998). Exploring community attitudes to water conservation and effluent reuse. A consultancy report prepared by Open Mind Group, St Kilda, Victoria.

[10] Water Corpoeration of Western Australia (2003). Community attitudes and public perceptions, Water Recycling Workshop. 